\title{
AS REPRESENTAÇÕES SOCIAIS DE PEDAGOGAS SOBRE INDISCIPLINA NA ADOLESCENCIA NO CONTEXTO ESCOLAR
}

\author{
Antonio Batista Alves Neto* \\ Solange Franci Raimundo Yaegashi*
}

RESUMO: O presente estudo teve como objetivo identificar as representações sociais de pedagogas sobre a indisciplina na adolescência. Como referencial teórico-metodológico, utilizou-se a Teoria das Representações Sociais, a qual busca investigar como se formam e como funcionam os sistemas de referência utilizados para classificar pessoas e grupos e para interpretar os acontecimentos do cotidiano. Participaram desta pesquisa dez pedagogas de uma cidade do noroeste do Estado de Paraná. A pesquisa é de natureza qualiquantitativa; para a coleta dos dados, utilizaramse os seguintes instrumentos: a) Questionário Sociodemográfico e b) Roteiro de Entrevista Semiestruturada. Para a análise dos dados, elaboraram-se categorias de análise. Os resultados revelam que as representações sociais das pedagogas sobre indisciplina na adolescência acabam se aproximando de uma concepção que naturaliza o comportamento do indivíduo, uma vez que a própria visão sobre o que viria a ser o "adolescente" apresenta indícios de não haver uma base histórica e teórica sólida para esse conceito. Chegou-se à conclusão que as representações sociais de pedagogas sobre indisciplina na adolescência está centrada em uma visão superficial sobre o que seria o ser "adolescente" e principalmente sobre qual é, de fato, o contexto gerador da indisciplina, o que fez com que as pedagogas acabassem naturalizando, em alguns momentos, e inconscientemente, as ações dos adolescentes em seus contextos escolares.

PALAVRAS-CHAVE: Representações sociais; Pedagogas; Indisciplina; Adolescência.

\section{SOCIAL REPRESENTATIONS OF PEDAGOGUES ON THE LACK OF DISCIPLINE OF ADOLESCENTS IN SCHOOL}

ABSTRACT: Current analysis identifies pedagogues' social representations on the lack of discipline in adolescence. The Theory of Social Representations was employed

Docente no Ensino Fundamental pela Secretaria de Educação do município de Sarandi (PR); Docente convidado no curso de Letras EAD pelo Centro Universitário de Maringá (UNICESUMAR), Brasil.

E-mail: prof.antoniob@gmail.com

** Docente Associada do Departamento de Teoria e Prática da Educação e do Programa de Pós-graduação em Educação da Universidade Estadual de Maringá (UEM), Brasil. 
as a theoretical and methodological foregrounding. It investigates how reference systems used to classify people and groups are formed and function to interpret day-to-day events. Ten pedagogues from a town in the north-western region of the state of Paraná participated in current quality and quantity research. The following tools were employed for data collection: a) Social and Demography Questionnaire and b) Half-Structured Interview. Categories of analysis were prepared for the analysis of data. Results show that pedagogues' social representations on lack of discipline during adolescence are close to the idea that naturalizes the behavior of the individual. The above occurs because one's idea of what is an adolescent reveals traces with no true historical and solid basis on the concept. Results show that the pedagogues' social representations on the lack of discipline in adolescence focuses on a superficial idea of what would be 'the adolescent' and mainly what is the generating factor of indiscipline. At specific moments, the pedagogues, unaware, naturalized the actions of adolescents in their school context.

KEY WORDS: Social representationsis; Pedagogues; Adolescence.

\section{INTRODUÇÃO}

A problemática da "indisciplina escolar" é, ainda hoje, um grande desafio para aqueles que estão no dia a dia do espaço educativo. Uma pesquisa realizada pela Organização para Cooperação e Desenvolvimento Econômico (OCDE), divulgada pelo site revista Educação (2016), apontou que o Brasil é número 1 "em mau comportamento na sala de aula". Essa pesquisa internacional sobre ensino e aprendizagem avaliou 34 países entre 2008 e 2013 e indicou que são os professores brasileiros que gastam mais tempo em sala de aula para manter a "ordem" e poder iniciar o conteúdo. A pesquisa revela ainda que, em 2008, 18\% dos professores entrevistados alegavam gastar muito tempo para iniciar as aulas por conta da falta de ordem. Já em 2013, esse número subiu para 20\%, enquanto a média dos demais países está em 13\% dos docentes com esse relato. Segundo a pesquisa, a indisciplina é generalizada no Brasil, ao contrário do que muitos imaginam, "os números de estudantes com mau comportamento são quase os mesmos nas escolas públicas ou particulares, a diferença foi de apenas três pontos" (REVISTA EDUCAÇÃO, 2016, p. 1). 
Lopes e Gomes (2012), ao abordarem o conceito de indisciplina do ponto de vista histórico, chegaram à conclusão de que o termo se ampliou nas últimas décadas, sendo necessário analisar esse fenômeno como multicausal. Nos termos dos autores, "[...] para compreendê-lo é necessário considerar vários fatores, como: a vida escolar do aluno, a escola, a turma e o professor [...] a família e a sociedade [...]" (LOPES; GOMES, 2012, p. 264). Enfim, não é fácil definir pontualmente o que vem a ser a indisciplina, mas faz-se necessário observar o contexto em que as situações se desenvolvem e como ocorrem, especialmente nas escolas de ensino médio, cujo público é composto essencialmente por adolescentes.

O Estatuto da Criança e do Adolescente (ECA) (BRASIL, 2012) limita a adolescência a um período determinado na faixa etária entre os 12 e os 18 anos de idade. No entanto, Digiácomo e Digiácomo (2011) afirmam que essa caracterização encontrada no artigo $2^{\circ}$ do ECA deve ser observada e utilizada apenas como um aspecto legal, uma vez que podemos contar com outras ciências que apresentam uma interpretação mais ampla do termo "adolescência".

Dessa forma, busca-se na psicologia, mais especificamente na abordagem histórico-cultural, a definição do conceito de adolescência. Maio e Siqueira (2011) declaram que a adolescência não pode ser vista como uma "fase" ou algo natural. Ao contrário, trata-se, segundo Bock (2001), de uma condição social, produzida historicamente pelos indivíduos em cada tempo e em cada região. Uma concepção que pode variar drasticamente de cultura para cultura, e na qual, normalmente, encontram-se transformações biológicas, que adaptam o corpo humano para a reprodução (puberdade), um momento de constantes alterações hormonais que têm em si o potencial de mexer com o humor, por exemplo, mas que não pode ser reduzida ou concebida como uma condição imutável.

Paula e Dayrell (2013) assinalam que o comportamento do adolescente que frequenta o ensino médio sofre grande variação em virtude do contexto sociocultural. Os autores ressaltam que uma caracterização possível desse público é a "heterogeneidade", grandes variações de turma para turma, de grupo para grupo e até mesmo entre os indivíduos de uma mesma sala de aula, o que sem dúvida gera um grande desafio para a escola atual. Podem-se observar novas formas de pensar e de agir que fazem parte da construção da identidade do ser e que trazem 
"possibilidades de novas escolhas ligadas à religião, sexualidade, afetividade e estilos culturais", resultantes das referidas transformações biológicas, psicológicas e também sociais (PAULA; DAYRELL, 2013, p. 31). Enfatiza-se, então, que se trabalha com a compreensão de que existem "adolescências", ou seja, variadas formas de ser adolescente e não apenas uma adolescência.

Diante da complexidade de tal conceito, neste estudo teve-se como objetivo identificar as representações sociais de pedagogas sobre a indisciplina na adolescência no contexto escolar. Selecionou-se a classe das pedagogas para observar porque se trata de um grupo de profissionais que por sua formação específica e atuação na escola tem o potencial de revelar representações amplas a respeito de diversos temas recorrentes dentro da escola.

Como referencial teórico-metodológico, utilizou-se a Teoria das Representações Sociais (TRS), inicialmente desenvolvida por Serge Moscovici (19252014). Essa teoria toma forma a partir dos estudos que compõem a tese de doutorado de Moscovici. Nessa tese, que posteriormente se tornou o livro A psicanálise, sua imagem e seu público (2012), o autor introduz os conceitos de ancoragem e de objetivação que constituem a base dessa teoria. Nesse estudo, Moscovici (2012) evidencia a grande relevância do papel da comunicação para a formação das representações sociais enquanto fenômeno, ou seja, para a produção de um conhecimento popular. É por meio da comunicação e seu caráter persuasivo que se forma um reservatório de imagens que possibilitam classificações sobre tudo ao nosso redor. Com isso, criamos "protótipos", como explica Moscovici (2012), sobre o que pode ser "certo" ou "errado". Esse processo de formação de protótipos, de conceitos, de criação de imagens, mediante os mais diversos meios de comunicação, está situado dentro do conceito de ancoragem.

O processo de ancoragem ${ }^{3}$, conforme Moscovici (2015, p. 61), é o primeiro passo para tornar familiar aquilo que não é. É o primeiro momento em que se aproxima de um conceito distante, é a base para a formação das representações sociais, trata-se de um processo cognitivo. Por outro lado, a objetivação "aparece, então, diante de nossos olhos, física e acessível" (MOSCOVICI, 2015, p. 72), e é na qual se materializa aquilo que, no primeiro momento, foi acomodado no processo

\footnotetext{
Empregamos o termo "ancoragem" ligado exclusivamente à Teoria das Representações Sociais de Serge Moscovici. Podemos encontrar esse termo também em outras teorias, como, por exemplo, na Teoria de Aprendizagem Significativa de David Ausubel (1918-2008).
} 
de ancoragem. Nesse âmbito, Jodelet define a objetivação como aquilo que dá "corpo aos esquemas conceituais" (JODELET, 1990, apud ALVES-MAZZOTTI, 2008, p. 29).

Apresentadas as discussões iniciais, nas próximas seções discorrem-se sobre a metodologia utilizada, os resultados obtidos e as considerações relativas à pesquisa empreendida para a elaboração deste texto.

\section{METODOLOGIA}

\subsection{PROCEDIMENTOS PARA A COLETA DE DADOS}

Os procedimentos que envolveram a coleta de dados podem ser divididos em três momentos. No primeiro, solicitou-se autorização por escrito, via carta de anuência, ao Núcleo Regional de Educação (NRE) de uma cidade do noroeste do Paraná. No segundo, com a devida autorização em mãos, apresentou-se o projeto de pesquisa ao Comitê Permanente de Ética em Pesquisa Envolvendo Seres Humanos (Copep) da Universidade Estadual de Maringá (UEM). A coleta de dados atendeu às diretrizes da resolução n ${ }^{0}$ 196, de 10 de outubro de 1996, do Conselho Nacional de Saúde e foi aprovada pelo Comitê de Ética em Pesquisa Envolvendo Seres Humanos da UEM pelo processo $\mathrm{n}^{\mathrm{O}}$ 51782515.2.0000.0104, Parecer consubstanciado $\mathrm{n}^{\mathrm{O}}$ 1.407.194. O terceiro passo foi entrar em contato por telefone para agendar o horário a fim de que pudéssemos apresentar os objetivos do projeto e realizar as entrevistas.

Antes do início de cada entrevista, explicaram-se novamente os objetivos da entrevista e solicitou-se aos participantes que assinassem o Termo de Consentimento Livre e Esclarecido. Cada participante respondeu inicialmente ao questionário sociodemográfico e, na sequência, realizaram-se as entrevistas, as quais foram gravadas e transcritas na íntegra e duraram, em média, 45 minutos.

\subsection{LOCAL DE PESQUISA E SUJEITOS}

A pesquisa foi realizada em escolas do ensino médio da rede estadual de uma cidade do noroeste do Paraná. Os dados do IBGE (2014) revelam que a 
cidade possui uma população estimada de 391.698 habitantes. Com base nos dados disponibilizados pelo Núcleo Regional de Educação - NRE (2015), há 39 escolas estaduais nessa cidade. Todavia, a amostra está restrita a aproximadamente $27 \%$ dessas escolas, o que equivale a nove escolas. Em uma das escolas, entrevistaram-se duas pedagogas, uma vez que o número de turmas no ensino médio era elevado. Participaram do estudo dez pedagogas.

\subsection{INSTRUMENTOS}

Foram utilizados um questionário sociodemográfico, com a intenção de caracterizar o público investigado, e um roteiro de entrevista semiestruturada, cujo objetivo foi investigar as representações sociais das pedagogas sobre indisciplina.

Spink (2013) explica que por ser uma análise centrada na totalidade do discurso, a entrevista tende a ser demorada, como no caso desta pesquisa, e consequentemente os estudos que fazem uso dessa metodologia usam poucos sujeitos, que devidamente contextualizados, "têm o poder de representar o grupo no indivíduo" (SPINK, 2013, p. 105).

\subsection{PROCEDIMENTOS PARA ANÁLISE DOS DADOS}

Os procedimentos para análise dos dados coletados foram divididos em duas partes. A primeira refere-se ao tratamento dos dados coletados pelo questionário sociodemográfico, que se limitou à análise quantitativa. A segunda reporta-se ao tratamento destinado ao questionário sociodemográfico, para o qual se empreendeu uma análise qualitativa, uma vez que foram elaboradas categorias de análise com base na proposta de Bardin (1977), com a finalidade de analisar as falas das pedagogas.

Sendo assim, após leituras das entrevistas transcritas, criam-se as seguintes categorias de análise: 1) representações sociais sobre o adolescente e 2) representações sociais sobre o conceito de indisciplina. 


\section{RESULTADOS E DISCUSSÕES}

\subsection{PERFIL SOCIODEMOGRÁFICO DAS PEDAGOGAS}

Com base na análise dos dados do questionário sociodemográfico, observase que das dez pedagogas entrevistadas, todas apresentavam sua formação inicial na área da pedagogia. No tocante à formação complementar, nove $(90 \%)$ pedagogas tinham uma ou mais especializações lato sensu na área da educação e apenas uma (10\%) tinha mestrado em educação.

Em relação ao tempo de atuação, quatro (40\%) tinham mais de 20 anos de atuação na área, outras quatro (40\%) tinham entre dez e 15 anos de atuação, uma (10\%) tinha entre cinco e dez anos e outra (10\%) entre 15 e 20 anos de atuação. Portanto, o tempo médio de atuação das participantes da pesquisa era de 21,4 anos.

Das entrevistadas, cinco (50\%) trabalhavam em mais de uma escola e outras cinco (50\%) trabalhavam apenas em uma escola.

Sobre a jornada de trabalho, oito (80\%) trabalhavam 40 horas semanais, enquanto duas (20\%) trabalhavam apenas 20 horas por semana.

De todas as entrevistadas, oito (80\%) não exercem nenhuma outra ocupação além da coordenação pedagógica, uma (10\%) exercia outra ocupação fora da área e uma (10\%) não respondeu a essa questão do questionário.

E para finalizar, a idade média das participantes da pesquisa era de 46 anos.

\subsection{DADOS REFERENTES ÀS ENTREVISTAS SEMIESTRUTURADAS}

\subsubsection{Representações sociais sobre $\mathrm{o}$ adolescente}

As representações sociais das pedagogas aqui entrevistadas sobre a adolescência aproximam-se muito dos conceitos ligados ao pensamento de Henri Wallon e aos estágios do desenvolvimento, como mostra Galvão (2012).

Ao se referir ao desenvolvimento do ser humano, Wallon (1979 apud GALVÃO, 2012) considera que os fatores orgânicos e sociais têm grande influência nos estágios do desenvolvimento. Nas palavras da autora, o "homem é determinado fisiológica e 
socialmente, sujeito, portanto a uma dupla história, a de suas disposições internas e a das situações exteriores que encontra ao longo de sua existência" (GALVÃO, 2012, p. 29). Mas ao mesmo tempo em que lida com esses fatores (fisiológico e social), a perspectiva walloniana lança mão dos conceitos de "fases", "etapas", "períodos" e "estágios" do desenvolvimento. Essas fases e estágios, como aponta Galvão (2012), sofrem alterações, não são homogêneas e nem lineares, mas imutáveis em seu processo sequencial, uma vez que diferentemente do que postula a perspectiva histórico-cultural, essas fases não deixarão de existir independe do contexto histórico, social ou geográfico. Galvão (2012, p. 39) enuncia que tais estágios "sucedem-se numa ordem necessária", sendo cada um deles essencial para o desenvolvimento da próxima etapa. O que forma o "contexto do desenvolvimento", de acordo com Galvão (2012, p. 39), são os "aspectos físicos do espaço, as pessoas próximas, a linguagem e os conhecimentos próprios a cada cultura", o que mesmo assim não inviabiliza a existência dos estágios do desenvolvimento na perspectiva walloniana. O que ocorre é que "o ritmo pelo qual se sucedem as etapas é descontínuo, marcado por rupturas, retrocessos e reviravoltas" (GALVÃO, 2012, p. 41).

Corroborando Galvão (2012, p. 43-44), os estágios abordados por Wallon, da infância até chegar à adolescência, são os seguintes: "estágio impulsivo-emocional", que se refere ao primeiro ano de vida do ser humano; o "estágio sensório-motor e projetivo", que vai até o terceiro ano de vida; o "estágio do personalismo", que vai dos três aos seis anos de vida; e o "estágio categorial", que se inicia aos seis anos de vida até chegar à adolescência, interesse desta pesquisa.

No estágio da adolescência, a crise pubertária rompe a "tranquilidade" afetiva que caracterizou o estágio categorial e impõe a necessidade de uma nova definição dos contornos da personalidade, desestruturados devido às modificações corporais resultantes da ação hormonal. Este processo traz à tona questões pessoais, morais e existenciais, numa retomada da predominância da afetividade (GALVÃO, 2012, pp. 44-45).

Cabe destacar que a perspectiva histórico-cultural com a qual se trabalha para entender o conceito de "adolescência" não nega as questões hormonais e afetivas relacionadas ao período denominado "puberdade", tampouco as modificações corporais. O ponto de distanciamento dessas perspectivas se dá justamente na 
condição social, que é mais determinante na vertente histórico-cultural do que na walloniana. É histórica em uma e não é em outra; pode ser determinada por questões culturais em uma e não pode em outra. Adotamos a visão de que "a adolescência é uma demarcação cultural, isso significa que o contexto social [...] família, escola, amigos/as, meios de comunicação, entre outros, influencia e interfere de forma significativa o seu modo de estar e de agir no mundo" (MAIO; SIQUEIRA 2011, p. 72), e até mesmo a possibilidade de existência de uma "adolescência" ou não, fato que não ocorre na perspectiva walloniana, uma vez que o meio social pode influenciar muito o processo de maturação, mas não o fará deixar de existir dependendo da condição de existência do ser.

Essa breve retomada teórica se fez necessária porque sete das dez pedagogas entrevistadas citaram, ao definir o seu público adolescente, o termo "fase" ou "período". E outras duas pedagogas fizeram referências diretas às condições hormonais e comportamentais imutáveis das quais Wallon assinala com mais propriedade. Com isso, nove pedagogas utilizaram conceitos wallonianos para se aproximar de um conceito que, em sua acepção, aparentemente é vago, a adolescência, buscando tornar familiar o que não é muito bem compreendido por elas.

Para a compreensão do conceito moscoviciano de ancoragem, foi preciso mostrar onde estavam as bases e em qual dimensão teórica estava ancorada, ainda que inconscientemente, já que nenhuma pedagoga entrevistada citou uma ou outra perspectiva.

Para exemplificar, buscaram-se algumas falas das participantes da pesquisa. A pedagoga P1, ao ser questionada sobre o que seria a adolescência, reflete: "[Respirou profundamente] $\mathrm{O}$ adolescente é uma pessoa que está em fase de transição, né, consigo mesmo. Então, ele é muito confuso em alguns momentos. E ele também está tentando se definir, enquanto, né, ser [...]". Afirma ainda, para além da imutabilidade de sua condição, uma característica universal: "Então, a gente sabe que é uma característica do adolescente confrontar com as regras né. [...] [risada]" (P1).

A pedagoga P2 também expressou o conceito de fase, reforçando a perspectiva da P1 de que "quebrar regras" é uma característica desse "período": 
Que ele, ele tá mudando pra ele, está em mudança, e ele sabe disso, mas não basta ele estar em mudança com o corpo dele, ele quer mudar! [...] Ele quer mudar o mundo ele quer mudar, por exemplo, uniforme ele não quer vir de uniforme. Porque pra ele não é essencial. [...] E que ele é o dono da verdade. [...] Adolescente é isso, sou contra porque eu sou contra [...] ele vai passar essa fase de transição com sabedoria (P2).

E o que se pode verificar, ainda na afirmação da P2, é que suas representações estão ancoradas em suas experiências pessoais como profissional e como mãe, pois relatou: "Apesar da idade, por eles serem diferentes, mas por eu ser mãe, né? Eu tenho noção do que é isso. É muito tranquilo [...]” (P2).

A pedagoga P5 citou o conceito de "fase": "[...] Entre esse limite aí, de infância e a fase adulta é uma fase de muito conflito pra ele, né [...]" (P5). E as pedagogas P3, P4, P7, P8, P9 e P10 citaram ou fizeram referência ao termo período, como nessa afirmação: "Então é outro período, né, de transformação também. Essa adolescência é um período de transformação. [...] (P10), levando em consideração, ainda, questões hormonais desse "período": "Eu vejo o adolescente assim é, como é que fala, uma oscilação de humor, é ele está feliz, alegre, nervoso, por conta das questões hormonais, né [...]” (P3).

Nesse sentido, indaga-se: Quais as consequências dessa perspectiva? Se tomar a adolescência como um período natural do desenvolvimento, sem as considerações próprias de uma perspectiva como a histórico-cultural, corre-se o risco de naturalizar as ações dos adolescentes, seus problemas e desafios. Naturalizar no sentido de tornar "normais", "comuns" certos atos que prejudicam o processo de ensino e aprendizagem, considerando que se está lidando com a questão no contexto escolar, a exemplo da fala da pedagoga P2: "A indisciplina mais comum, que não é tido como indisciplina [...] muito tranquilos. Têm os casos de alunos nervosos, mas no meu conceito não é indisciplina [...]".

Diante de todas essas falas, verifica-se que apenas uma pedagoga compreende o adolescente de uma forma mais ampla, problematizadora:

É, o adolescente é assim se você for, se a gente fosse, é entendê-lo nesse contexto, né, ele reflete toda a questão social. Reflete as, as exigências que a gente tem sociais, as exigências é, mesmo como a gente pode assim, da própria família, né. Então em termos gerais 
o adolescente ele é aquilo que a sociedade exige dele por isso que a gente diz que, né, por exemplo, eu como adolescente que tenho cinquenta e dois anos, fui uma adolescente, o adolescente hoje é outro, né. Então ele é fruto dessa sociedade, dessas relações. Então, muitas vezes, como e falei lá, um aluno que não tem uma organização porque não foi dada a ele essa forma de organização, desse, dessas regras (P6).

No caso dessa assertiva da pedagoga $\mathrm{P} 6$, apesar de não haver citação de autores ou de uma linha teórica clara, sua fala evidencia uma determinada concepção, ou seja, seu conceito de adolescência ancora-se na abordagem histórico-cultural.

$\mathrm{Na}$ seção seguinte, discorre-se acerca das representações das pedagogas sobre o termo 'indisciplina'.

\subsubsection{Representações sociais sobre o conceito de indisciplina}

Observou-se, na análise das representações sociais do conceito de "indisciplina" por parte das pedagogas, uma tendência neutralizadora de alguns comportamentos dos adolescentes. Constataram-se ainda discursos às vezes contraditórios de uma mesma participante. Ao mesmo tempo em que se verificou em cada pedagoga uma perspectiva que naturaliza e justifica comportamentos inadequados ao bom andamento do processo de ensino e aprendizagem, posteriormente em outro ponto observou-se nessa mesma pedagoga uma visão mais ampla e completa sobre o problema em pauta. Exemplifica-se: a pedagoga $\mathrm{P} 4$ alegou não ver "certas situações" como situações de indisciplina: "Então, as indisciplinas que têm aqui é aquilo que eu te falei, a gente coloca como indisciplina, mas eu como pedagoga não vejo que é uma indisciplina assim. É atraso de primeira aula durante o ano todo é o que mais tem [...]" (P4).

Por outro lado, essa mesma pedagoga foi uma das poucas que expressou uma concepção de "indisciplina" mais ampla. Ao ser questionada sobre o que é indisciplina em sua perspectiva, ela respondeu da seguinte forma:

[...] eu acho muito relativa a questão da indisciplina. A indisciplina pode partir do professor, e eu estou falando isso aqui para você e claro que pra ele lá às vezes é muito difícil eu falar pra ele, né. Então pode partir [...] da organização, do planejamento, né. Da falta de 
diálogo com o aluno [...] como também pode partir dos alunos, né. [...] Então é, eu vejo isso, a indisciplina, eu acho que de todos os lados sabe. "A culpa é da família, a culpa é da escola", né [...] (P4).

É possível constatar na fala da pedagoga $\mathrm{P} 4$ que mesmo naturalizando alguns comportamentos, acaba olhando as causas do problema de uma forma mais completa. Nesse contexto, questiona-se: A que se deve esse fenômeno? É nesse ponto que a Teoria das Representações Sociais (TRS) auxilia na compreensão dos diferentes discursos. A TRS possibilita verificar que mesmo sem ter consciência, as pedagogas estão fazendo uso de uma concepção relacionada ao "adolescente" que pode não corresponder à realidade de sua atuação. Ou seja, a falta de fundamentação teórica pode gerar situações como essa que se observou na pedagoga P4, em que não existe uma coerência na fala do início ao fim. Começa a pensar por uma perspectiva, em seguida modifica e toma outra concepção, fazendo de sua prática um "emaranhado" de metodologias, tornando-as pouco eficientes. Salienta-se que não se está "advogando" em prol de uma perspectiva teórica exclusiva, mas pela consciência daquilo que se está fazendo, seja com qual teoria, e essa consciência teórico-metodológica só é constituída com muito estudo, com formação contínua.

Ainda a respeito de algumas tendências neutralizadoras de certos comportamentos, apresentam-se as falas das pedagogas P2, P3 e P6. Ao serem questionadas se existem muitas situações de indisciplina em sua escola, a pedagoga P2 afirmou que: "Não! De indisciplina no Ensino Médio! A gente até tem a indisciplina no sexto ano, mas no Ensino Médio Não. Não!”.

Porque pra mim a indisciplina é agressão, xingar, bater, quando extrapola. Então a gente tem aquele normal de escola... O aluno fica nervoso, sai da sala e bate a porta, né, aí o professor leva pra você como indisciplina e a hora que você senta com ele e vai conversar, o professor chega, ele pede desculpas. Então, não chega a ser uma indisciplina, né (P2).

Busca-se não rotular a ação por ação, dizendo se "isso é" ou não indisciplina, porém parte-se do princípio de que a indisciplina não se trata de um comportamento unicamente ligado ao aluno, mas de um contexto que impede o processo de ensino e aprendizagem, como pondera Vasconcellos (2009) quando afirma que a indisciplina está situada na relação escolar como um todo, que atinge 
tanto o aluno quanto o preparo didático do professor. Sendo assim, o que se indaga nesse momento é: Um aluno sair nervoso e batendo a porta não caracterizaria uma situação de indisciplina? É evidente que ainda não se está levando em conta todos os fatores abordados a seguir, como a questão essencial: "o que houve para o aluno sair de sala dessa forma?". Devem-se ainda considerar alguns fatores relacionados, também, à postura docente como geradores de momentos como esse relatado, tais como permissividade, indiferença, autoritarismo, falta de confiança mútua, normas vagas e procedimentos desajustados, com diretivas pouco precisas, falha na comunicação etc. (LOPES; GOMES, 2012). Enfim, fatores determinantes para compreender de forma completa tais situações.

$\mathrm{Na}$ fala da pedagoga $\mathrm{P} 6$, encontra-se o termo "comum", que ratifica as conclusões às quais chegamos sobre a naturalização de certas ações: "[...] Uso de celular, às vezes um bate boca com o professor, mas é uma coisa muito dentro de um parâmetro comum [...]".

Solicitou-se também às pedagogas que falassem sobre seus conceitos de "indisciplina", e destacam-se algumas falas:

[...] A gente tem um guia do aluno com um monte de regras que o aluno [...] tem que seguir, e não seguindo aquilo vai gerar indisciplina [...], falar palavrão em sala é um ato de indisciplina, é [...] Jogar bolinha de papel, isso não pode, [...] o uso do celular é proibido em sala de aula. É uma coisa que eles burlam [...] (P1).

A pedagoga P1 define indisciplina como "O não cumprimento das regras". Verificou-se que na escola onde essa pedagoga trabalha a indisciplina é tudo o que vai contra a convenção social estabelecida pelo guia do aluno.

Ainda para a pedagoga $\mathrm{P} 1$, as situações de indisciplina são assim caracterizadas: "[...] quando o aluno é sem educação, responde, quando entra palavrões, essas coisas. Agressividade de bater, de jogar carteira no chão, né. Para mim, indisciplina é isso, quando tem agressividade e ser mal educado [...]". Já para a pedagoga P3, nem todas essas questões são vistas como situações de indisciplina, pois para ela a indisciplina se limita a questões físicas: "[... ] Então assim, a indisciplina para mim é o que eu falei no começo mesmo, é algo mais físico assim, né” (P3).

A pedagoga $\mathrm{P} 7$ pontua que a indisciplina ocorre "[...] quando o aluno não 'tá' realizando a atividade, não 'tá' estudando, então ele 'tá' apático, 'tá' indiferente, 
ou ele 'tá' agressivo, né, respondendo de forma agressiva um colega ou um professor. [...]". Já para a P9, a "Indisciplina [...] é o ato de você não conseguir se adequar, né, de acordo com as regras estabelecidas no meio em que você vive socialmente [...]".

Pediu-se também para as pedagogas relatarem as situações de indisciplina mais comuns em seus espaços escolares envolvendo seus alunos adolescentes e, com base nos relatos, elaborou-se o Quadro 1.

Quadro 1. Situações mais comuns de indisciplina de acordo com as pedagogas entrevistadas

\begin{tabular}{|c|c|}
\hline PEDAGOGA & SITUAÇÃO DE INDISCIPLINA COMUM NA ESCOLA \\
\hline P1 & Atrapalhando a aula com muito conversa e brincadeira $[\ldots]$ celular $[\ldots]$. \\
\hline $\mathrm{P} 2$ & $\begin{array}{l}{[\ldots] \text { o celular na sala, né. E eles, insistem e usam quando eles filmam }} \\
\text { alguma coisa que não deveria ser filmado }[\ldots] \text {... }\end{array}$ \\
\hline $\mathrm{P} 3$ & $\begin{array}{l}\text { [...] seria o celular e o atraso de primeira aula. É o atraso de primeira } \\
\text { aula é grave! É grave porque você chega na sala de aula têm três alunos, } \\
\text { quatro alunos [...]. }\end{array}$ \\
\hline $\mathrm{P} 4$ & $\begin{array}{l}\text { É Bullying, }[\ldots] \text { E é comum, é, agressões verbais, }[\ldots . .] \text { de vai tomar no cu, } \\
{[\ldots . . \text { 'pau no cu' [risada] }[\ldots] \text { celular }[\ldots] .}\end{array}$ \\
\hline P5 & $\begin{array}{l}{[\ldots] \text { eles ficarem andando pela sala, correndo pela sala e gritarem. }[\ldots]} \\
\text { celular. }\end{array}$ \\
\hline P6 & $\begin{array}{l}{[\ldots] \text { muita conversa na sala, eles conversam alto }[\ldots] \text { uma dificuldade de, }} \\
\text { de entender aquela sala como um contexto escolar }[\ldots] \text { celular }[\ldots] .\end{array}$ \\
\hline P7 & {$[\ldots]$ é quando o aluno não realiza a atividade. $[\ldots]$ celular $[\ldots]$. } \\
\hline P8 & $\begin{array}{l}{[\ldots] \text { os alunos é saem da sala na hora que dá o sinal de intervalo de uma }} \\
\text { aula pra outra }[\ldots] \text { celular }[\ldots] \text {. }\end{array}$ \\
\hline P9 & Eu diria que é desacato ao professor $[\ldots]$. \\
\hline P10 & $\begin{array}{l}{[\ldots] \text { o celular na escola, }[\ldots] \text { e às vezes ele pega o celular, fala que é pra ver }} \\
\text { a hora e não pode, }[\ldots] \text { conversas, brincadeiras na sala de aula, né, que } \\
\text { atrapalha de o professor }[\ldots . .] \text { entrar no horário de aula }[\ldots] \text { desrespeitar o } \\
\text { professor, xingar o professor, xingar o outro aluno. }[\ldots] .\end{array}$ \\
\hline
\end{tabular}

Fonte: Os autores.

Resumidamente, todos os relatos observados no Quadro 1 são situações que interrompem a aula de alguma forma, e todas essas situações são localizadas apenas na pessoa do aluno. 
É importante enfatizar que não se discorda das situações de indisciplina relatadas, bem como das caracterizações e descrições feitas pelas participantes da pesquisa. O que se busca problematizar é que o processo de naturalização e individualização do problema da indisciplina coloca-se de maneira complexa.

Para prosseguir, frisa-se que nas falas das pedagogas P5 e P10 é possível constatar que ao expressarem suas concepções de indisciplina, limitam esse problema à figura do aluno: "Eu considero como indisciplina a falta de controle, da ordem. Mas o que vem ser a ordem? [...] uma sala que conversam bastante são indisciplinados? Não necessariamente [...] É o que transpassa da ordem para mim, do limite da ordem [...]" (P5). E para a P10, a "Indisciplina é quando o aluno, ele é, sai né, destoa daqueles combinados prévios, né, [...] entre os próprios alunos da sala de aula, com o professor, com as regras da escola [...]".

Dessa forma, observa-se que as representações sociais encontradas nas falas objetivadas pelas pedagogas retomam uma pedagogia tradicional, como apontam Lopes e Gomes (2012), pois se trata de um conceito centrado na figura do aluno, com poucas variações.

Assinala-se que as representações sociais sobre indisciplina encontradas nesta pesquisa fogem aos conceitos observados no trabalho de Alves-Mazzotti (2008), Vasconcellos (2009), Lopes e Gomes (2012) e Alves Neto (2016), que afirmam ser a (in)disciplina um fenômeno de origem multicausal, o que requer a necessidade da observação de vários fatores, sendo portanto incorreto limitar o conceito somente à figura do aluno. Considera-se que o aluno adolescente é o ser mais despreparado do espaço escolar, sendo assim deveria ser o último "culpado", caso fosse possível estabelecermos um. Não se trata de "vitimizar" o adolescente, mas apenas de colocar cada um dentro de suas responsabilidades, uma vez que a responsabilidade do profissional da educação é, também, buscar soluções coerentes a sua prática.

Observa-se que três das dez pedagogas entrevistadas apresentaram uma concepção mais próxima daquilo que se julga mais "funcional", mais apropriado à realidade do espaço escolar, indo para além da figura do adolescente ao tratar da indisciplina. $\mathrm{O}$ primeiro caso é encontrado na fala da pedagoga $\mathrm{P} 4$, já referido. $\mathrm{O}$ segundo foi verificado na fala da pedagoga P8 que, ao ser questionada sobre o que seria a indisciplina, disse: 
Indisciplina pra mim é, [...] A indisciplina é sempre pra te mostrar que alguma coisa não 'tá' legal, entendeu? Ou com o aluno, ou com a vida dele, ou com a escola, entendeu? [...] Pra mim indisciplina é isso, em relação a aluno. Quando eu percebo que 'tá' tendo uma rebeldia 'tá' sendo agressivo, 'tá' respondendo de tal forma, tá deixando de fazer tal coisa, entendeu? [...] A indisciplina ela, ela é isso, é tudo que de repente foge a um certo padrão que a gente determina. Não que seja um padrão fixo, entendeu? De ou certinho, ou isso, ou aquilo, mas é uma coisa que foge, entendeu? Totalmente à normalidade, ai nós procuramos investigar o que 'tá' acontecendo. Se é com o professor, se é a sala de aula, então vamos conversar com o professor vamos ver o que 'tá' acontecendo. É o aluno? É em casa? [...] (P8).

\section{E o terceiro caso foi encontrado na fala da pedagoga $\mathrm{P} 6$, que relatou:}

Eu acho que a indisciplina ela é sempre reflexo de alguma coisa, né? [...] Ela é sempre reflexo de alguma coisa, individualmente às vezes questões pessoais, desorganização em casa falta de, de atitude em sala, [...] E muitas vezes eles não têm isso em casa [...] A indisciplina, muitas vezes, é consequência da metodologia, do próprio conteúdo ministrado, do empenho do professor em organizar aquela sala, né $[\ldots](\mathrm{P} 6)$.

E para além das situações de indisciplina mais comuns relatadas pelas pedagogas, constantes no Quadro 2, constataram-se ainda outras situações gerais de indisciplina observadas em suas práticas.

Quadro 2. Situações gerais de "indisciplina” relatadas pelas pedagogas

(continua)

\begin{tabular}{|c|l|}
\hline PEDAGOGA & \multicolumn{1}{|c|}{ SITUAÇÃO DE INDISCIPLINA GERAL NA ESCOLA } \\
\hline P1 & $\begin{array}{l}{[\ldots] \text { Tipo situações de o aluno soltar uma bomba [risada] na escola }[\ldots], \text { passar }} \\
\text { cola pelo WhatsApp }[\ldots], \text { conversa durante a prova }[\ldots] \text { celular }[\ldots] .\end{array}$ \\
\hline P2 & {$[\ldots]$ aluno que $[\ldots]$ filmou alguma coisa na sala $[\ldots]$ celular $[\ldots]$.} \\
\hline P3 & $\begin{array}{l}{[\ldots] \text { enfrentamento professor, professor-aluno }[\ldots] \text { briga dentro de uma sala de }} \\
\text { aula, é, barulho, brincadeira fora de hora, conversa paralela, }[\ldots] \text { o celular porque } \\
\text { eles usam o tempo todo. }\end{array}$ \\
\hline P4 & $\begin{array}{l}{[\ldots] \text { desacato ao professor, nossa maior }[\ldots] \text { do aluno assim, ser descompromissado, }} \\
\text { enquanto estudo que eu vejo como indisciplina }[\ldots] \text { celular }[\ldots] .\end{array}$ \\
\hline
\end{tabular}


(conclusão)

\begin{tabular}{|c|c|}
\hline PEDAGOGA & SITUAÇÃO DE INDISCIPLINA GERAL NA ESCOLA \\
\hline P5 & $\begin{array}{l}{[\ldots] \text { saíram da sala em uma aula vaga pegaram os canetões e foram escrever nas }} \\
\text { paredes do banheiro e escreveram em todas as paredes do banheiro. [...] celular } \\
{[\ldots] \text {. }}\end{array}$ \\
\hline P6 & {$[\ldots]$ Uso de celular, às vezes um bate boca com o professor $[\ldots]$ celular $[\ldots]$} \\
\hline P7 & $\begin{array}{l}{[\ldots] \text { Os atrasos são constantes. Então, não chega para a primeira aula às sete } \mathrm{e}} \\
\text { meia, chega para a segunda }[\ldots] \text { celular }[\ldots] \text {. }\end{array}$ \\
\hline P8 & $\begin{array}{l}{[\ldots] \text { que entra senta e têm uns que dormem }[\ldots] \text { às vezes eu tenho é um celular }} \\
\text { aqui, [...] e que às vezes ficam olhando no horário de aula fazendo outras coisas } \\
\text { que às vezes não têm a ver com sala de aula }[\ldots] .+\end{array}$ \\
\hline P9 & $\begin{array}{l}{[. . .] \text { comportamentos inadequados do mais simples ao tráfico de drogas dentro da }} \\
\text { escola [...] Mais é mesmo é de agressão verbal, né. De mandar o professor tomar } \\
\text { no cu, dependendo da situação, né. De gritar }[. . .]\end{array}$ \\
\hline $\mathrm{P} 10$ & $\begin{array}{l}{[\ldots] \text { briga entre eles, quando há violência física, agressão verbal, né, também uma }} \\
\text { agressão verbal assim com palavrões e agressão física }[. . .] \text { celular }[\ldots] .\end{array}$ \\
\hline
\end{tabular}

Fonte: Os autores.

Verifica-se que as situações gerais relatadas no Quadro 1 não variaram muito em relação às situações descritas no Quadro 2, e algumas se repetem preocupantemente como agressões físicas, uso de palavras de baixo calão, atrasos etc. Mas uma da situações parece ser mais preocupante: o uso do celular por parte dos adolescentes como um fator para a indisciplina aparece na fala de nove das dez pedagogas tanto no Quadro 1 quanto no Quadro 2. Apenas a pedagoga P9 não citou em nenhum momento o celular como um fator de indisciplina em sua escola.

Para finalizar, retomam-se os conceitos de ancoragem e objetivação de Moscovici (2015), pois uma última análise se faz necessária. A pedagoga P7, ao ser questionada se na escola onde trabalha era necessário lidar com muitas situações de indisciplina, respondeu o seguinte: "Até que não [risada], como eu trabalhei em alguns lugares assim que tinham uma situação maior de stress vamos dizer de violência, eu diria que hoje não, 'tá' bem, bem tranquilo assim [...]" (P7). O que se observa é que o conceito de "escola indisciplinada" dessa pedagoga está ancorado em situações vivenciadas por ela. Sendo assim, seu protótipo, sua imagem de "indisciplina" é de algo muito mais complexo do que aquilo que enfrenta atualmente 
e, por isso, estabelece relação e faz essa comparação. Desse modo, sua objetivação, sua materialização do conceito é de que a escola atual é "tranquila", pois utiliza como parâmetro uma escola muito "pior".

Para concluir, a fala da pedagoga $\mathrm{P} 6$ também traz algumas evidências em termos de ancoragem e objetivação: "[...] Então assim, não porque a escola tem que ser rígida, tal, eu sou, eu tenho uma postura rígida, né, então eu sou geralmente... $\mathrm{E}$ trabalhei muitos anos com primeira à quarta e eu acho que pra ensinar tem que ter sentado, tem que 'tá' ouvindo. [...] (P6)". Nesse caso, a postura correta de um aluno adolescente está ancorada na perspectiva de um aluno dos anos iniciais do ensino fundamental, o que provavelmente leva a pedagoga a tentar reproduzir o seu padrão de "correto" ou adequado.

Diante dessas análises, verifica-se que é muito complexo tentar definir uma única forma de ver as representações sociais de pedagogas sobre a indisciplina na adolescência no contexto escolar. São inconstantes suas percepções do "adolescente" e falta uma fundamentação teórica para delimitá-lo. E mais, compreender o que é indisciplina em um ser sobre o qual a visão pode não estar corretamente contextualizada pode ser tarefa ainda mais difícil.

\section{CONSIDERAÇÕES FINAIS}

No presente estudo, objetivou-se identificar as representações sociais de pedagogas sobre indisciplina na adolescência. Por meio da análise das entrevistas, foi possível constatar que as representações sociais sobre o adolescente por parte das pedagogas apontam, desde o início, uma representação passiva desse ser, em que se espera que o adolescente haja de uma forma que não condiz com o atual contexto histórico e social da escola pública. Uma incoerência teórica também é notada, pois as pedagogas observam o ser "adolescente" por um viés walloniano e ao mesmo tempo adotam perspectivas relacionadas às pedagogias nova, libertadora $\mathrm{e}$ tradicional para tentar lidar com as situações que o envolvem. Assim, a naturalização do ser e de suas ações e a fragilização das bases teóricas são evidenciadas.

Reforça-se que não se está tentando inferir que as concepções teóricas 
ligadas ao maturacionismo ou ao sociointeracionismo "naturalizam" as ações do ser, ou seja, justificam os problemas dos indivíduos de acordo com sua fase do desenvolvimento. Apenas busca-se demonstrar que as pedagogas participantes da pesquisa estão caminhando para essa direção, apoiando-se, inconscientemente, nessa perspectiva. Frisa-se que ainda mais grave é o fator "inconsciente", uma vez que foi observado que mesmo fazendo uso dos termos "fase" ou "estágios", encontrados na perspectiva walloniana, as pedagogas não levam em conta o contexto social que se faz importante nessa perspectiva.

Cabe ressaltar ainda que em momento algum desta pesquisa buscou-se "pregar" uma perspectiva como a mais adequada à prática das pedagogas, pois apenas elas têm condições de verificar as necessidades de seu campo de atuação e delimitar o que seria mais adequado em termos de fundamentação. Reforça-se apenas é que é necessária uma coerência prático-teórica, pois sem isso não será possível vislumbrar bons resultados nas intervenções pedagógicas.

Com base nessas constatações, não se teve a intenção de culpabilizar unicamente o adolescente por seus comportamentos ou "criminalizá-lo" por suas ações. Muito pelo contrário, buscou-se compreendê-lo como ser histórico e social, porque não se acredita que haja outra forma de lidar com suas questões se não com didática e metodologia.

$\mathrm{Na}$ categoria "representações sociais sobre o conceito de indisciplina", vislumbra-se como é grande o desafio dos profissionais da educação. As situações relatadas levam qualquer profissional a um desgaste imenso. E por isso insiste-se na necessidade do devido preparo para a atuação no campo da educação. Ao mesmo tempo, observa-se que as situações de indisciplina relatadas são relacionadas aos alunos, e nada é dito sobre a "indisciplina docente"; verifica-se que o professor é ponto de partida para a indisciplina, mas não se pontua que este também é "indisciplinado" em suas tarefas.

As representações sociais das pedagogas sobre indisciplina na adolescência no contexto escolar acabam se aproximando de uma visão que naturaliza o comportamento do indivíduo, uma vez que a própria visão sobre o que viria a ser o "adolescente" apresenta indícios de não haver uma base histórica e teórica sólida para o conceito. Chegou-se à conclusão que as representações sociais das 
pedagogas relativas à indisciplina na adolescência estão centradas em uma visão superficial sobre o que seria o ser "adolescente" e principalmente sobre qual é, de fato, o contexto gerador da indisciplina, o que fez com que as profissionais acabassem naturalizando, em alguns momentos e inconscientemente, as ações dos adolescentes em seus contextos escolares.

Antes de finalizar esta breve análise, reforça-se, mais uma vez, a necessidade de compreender as perspectivas teóricas das quais se ocupa a formação dos profissionais da educação, pois elas são evidenciadas todos os dias em suas práticas, e o grande problema não é a pedagoga adotar uma ou outra perspectiva. O problema consiste no fato de que muitas vezes não se tem ideia de qual perspectiva se está adotando, nem do que se está fazendo. E sem a consciência de quais metodologias se está utilizando, fica impossível planejar resultados ou sequer alcançar algum. Nesse sentido, seria importante que mais pesquisas sobre essa temática fossem desenvolvidas, pois conhecer as representações sociais da equipe pedagógica e dos docentes é o passo inicial para que se possa pensar em como lidar com as situações de indisciplina no contexto escolar.

\section{REFERÊNCIAS}

ALVES NETO, A. B. As representações sociais de pedagogos(as) sobre indisciplina no ensino médio. 2016. Dissertação (Mestrado em educação) -Universidade Estadual de Maringá, 2016.

ALVES-MAZZOTTI, A. J. Representações sociais: aspectos teóricos e aplicações à educação. Revista múltiplas leituras, São Paulo, v.1, n. 1, p. 18-43, jan./jun. 2008. Disponível em: <https:/www.metodista.br/revistas/revistasims/index.php/ML/ article/viewFile/1169/1181>. Acesso em: 03 dez. 2015.

BARDIN, L. Análise do conteúdo. Lisboa: Edições 70, 1977.

BOCK, A. M. B. M. A psicologia e as psicologias. In: BOCK, A. M. B. M.; FURTADO, O.; TEIXEIRA, M. L. T. Psicologias: uma introdução ao estudo de Psicologia. 13. ed. São Paulo: Saraiva, 2001. p. 297-300. 
BRASIL. Secretaria de Estado da Família e Desenvolvimento Social. Estatuto da Criança e do Adolescente Lei 8.069/1990 e Legislação Complementar para Proteção Integral de Criança e Adolescente. Curitiba: SEDS, 2012.

DIGIÁCOMO, J. M.; DIGIÁCOMO, I. de A. ECA: Estatuto da Criança e do Adolescente anotado e interpretado. 2. ed. São Paulo: FTD, 2011.

GALVÃO, I. Henri Wallon: uma concepção dialética do desenvolvimento infantil. 21. ed. Petrópolis, RJ: Vozes, 2012.

IBGE. Instituto Brasileiro de Geografa e Estatística. População total do Paraná. 2014 Disponível em: <http://www.ibge.gov.br/estadosat/perfil.php?sigla=pr > Acesso em: 02 dez. 15.

LOPES, R. B.; GOMES, C. A. Paz na sala de aula é uma condição para o sucesso escolar: o que revela a literatura? Ensaio: Avaliação em Políticas Públicas em Educação, Rio de Janeiro, v. 20, n. 75, p. 261-282, 2012. Disponível em: < http:// www.scielo.br/pdf/ensaio/v20n75/03.pdf > Acesso em: 03 jan. 2015.

MAIO, E. R.; SIQUEIRA, J. Adolescência: questões histórico culturais. In: CAMARGO, J.S.; ROSIN, S.M. (Org.). Psicologia da educação para o curso de letras. Maringá: Ed. da EDUEM, 2011, p.69-80.

MOSCOVICI, S. Representações sociais: investigações em Psicologia Social. 2. ed. Petrópolis: Vozes, 2015.

MOSCOVICI, S. A psicanálise, sua imagem e seu público. Petrópolis, RJ: Vozes, 2012.

NRE. Núcleo Regional de Educação de Maringá. Colégios e escolas. Disponível em: <http://www.nre.seed.pr.gov.br/modules/conteudo/conteudo. php?conteudo=541> . Acesso em: 02 dez. 2015.

PAULA, S. G.; DAYRELL T. J. Conhecendo o jovem do ensino médio. Revista Presença Pedagógica, v.19, n. 110, mar./abr. 2013. 
REVISTA EDUCAÇÃO. Mau comportamento dos alunos é maior no Brasil, diz estudo. 2016. Disponível em: < http://www.revistaeducacao.com.br/mau-comportamento-dosalunos-e-maior-no-brasil-diz-estudo/> . Acesso em: 20 jun. 2016.

SPINK, M. J. Desvendando as teorias implícitas: uma metodologia de análise das representações sociais. GUARESCHI, P.; JOVCHELOVITCH, S. (Org.). Textos em representações sociais. 14. ed. Petrópolis, RS: Vozes, 2013. p. 95-118.

VASCONCELLOS, C. S. Indisciplina e disciplina escolar: fundamentos para o trabalho docente. São Paulo: Cortez, 2009.

Recebido em: 04 de janeiro de 2017 Aceito em:10 maio de 2017 